\title{
Adverse Positive Effect of Salinity Stress on Tomato Fruit Quality
}

\author{
Ghoname AA, Fawzy ZF* and AM El-Bassiony \\ Vegetables Research Department, National Research Centre, Dokki, Cairo, Egypt \\ *Corresponding Author: Fawzy ZF, Vegetables Research Department, National Research Centre, Dokki, Cairo, Egypt.
}

Received: April 23, 2019; Published: July 08, 2019

DOI: $10.31080 /$ ASAG.2019.03.0565

\begin{abstract}
Biotic and abiotic stress factors are eliminating plant growth, yield and fruit quality. Horticultural practices to maximize fruit yield and total production are concerned with cultivating plant at limited stress conditions using best production systems. It is also promising to stress plants to improve horticultural production and enhance fruit quality. However, Minor doses of some stressors couldhada stimulating effects ("positive stress" or eustress), on plant growth and yielded fruits. While, oppositely, higher doses of some stressors could also cause negative effects ("negative stress" or distress).

Salinity has been reported for positive effects for many vegetable crops. It is thought that salt stress adversely impacts yield traits of tomato; however has additionally a beneficial and positive effect in improving fruit flavor.

In this concern, tomato as a case study is considered one of the most important fruity vegetables, which will be reported to illustrate the positive effect of moderate salinity as a useful tool in an advanced tomato fruit production with better fruit quality.
\end{abstract}

Keywords: Salinity; Fruit Quality; Tomato

\section{Introduction}

Tomato is considered one of the most important vegetable crops in the world. Particularly for human health, tomato fruit is a main part of dietary meals in several countries as it is avital source of vitamins, minerals, and antioxidants. Recently, more attention has been concentrated on the bioactive ingredients and health aspects of tomato fruits. Current researches have shown that aroma and taste are the most significant aspects of any vegetable product. Producing high yields of tomato fruits with better quality and flavor is vital for guaranteeing satisfaction of consumers. Connections between greenhouse environment and salinity of the tomato plant are extremely complicated. Under excessive salinity conditions, crop yield and fruit quality, possibly affected adversely by salinity. Appropriate salinity could not be generalized because they vary according to the quality traits and the interactions between cultivars, climatic factors, concentration of the nutrient solution, as well as crop management. Tomato organoleptic quality is principally attributed to its sugar and acid content, aroma, while nutraceutical (nutritional) quality is mainly based on its mineral, vita- mins, flavonoid and carotenoid content. However, tomato flavour, is varies according to the cultivar and the growing conditions which was related to higher levels of reducing sugars and lower glutamic acid content Bucheli., et al [1]. Regarding tomato fruit sweetness and sourness, it is mainly characterized by the amount of sugars and acids contents Malundo., et al [2]. On the other hand, Carotenoids, are a strong source of vitamin A and antioxidizing agents, and therefore it play a vital role in counteracting cancer and heart diseases Krinsky [3,4]. Furthermore, tomato is rich in Flavonoids which has an anticarcinogenic effect Franscis., et al [5] and Verma., et al [6]. As well as, tomato fruit is reasonably rich in other favorable compounds such as ferulic, and cafeic acids, and have minor amounts of vitamin E Chen and Miller [7] and Grolier and Rock [8]. For that reasons, fruit quality enhancement by salt stress is acrucialtopic for highly nutritional value fresh products. Even though salinity is considered a stress factor that had a negative effects on fruit yield and quality but, the application of slight to moderate salinity levels, as well as the duration and time application of specific phenological stage could have favorable impact on chemical com- 
position and nutritional value of the final produced fruits [9-11]. For that reason, positive stress due to such conditions generate mechanisms of plant defense which motivate the synthesis of some bioactive compounds or lessen the content of bador undesirable compounds produced with negative stress conditions. The result of such technique is fruits with high content of bioactive secondary metabolites (carotenoids, phenolic compounds, organosulfuric compounds, polyamines, etc.) which improve nutritional properties and chemical composition and finally highly added value yield

\section{Effect of potential salt stress on tomato fruit yield}

For the Egyptian markets, the consumers favor the big size tomato fruits (150-200g). Unfortunately, higher salinity can markedly reduce the fruit growth rate and final fruit size became smaller. High salinity depresses the plant water potential, which will decrease the water flow into the fruit and consequently minimize fruit expansion rate Johnson., et al 1992.

Several studies at different growth conditions revealed that salinity levels higher than 2.3-5.1 mS/cm-1 markedly caused an disagreeable yield reduction Dorais., et al [12], Massey [13], Sonneveld and Van Der Burg [14] and Verkerke and Schols [15], reduced tomato fruit size according to high salinity is depending on the cultivar and not all tomato cultivars had the same response Cuartero and Fernandez-Munoz [16] or had been damaged by fruit cracking Abbott., et al. [17,18] and Cortés., et al [19]. or blossomend rot at the same level Adams and Ho [20,21], Belda and Ho [22] and Ho [23]. Generally, smaller fruit size tomato cultivars would be less affected by high salinity than cultivars with larger fruit size in respect to individual fruit weight Abbott., et al. [17] and the yield. Therefore under highly or moderately saline water, growing tomato of smaller-size cultivars could be auspicious and better than big-size fruit cultivars Abbott., et al [18].

\section{Effect of potential salt stress on tomato fruit quality}

\section{Physiological disorders}

The beneficial effects of salinity stress on tomato fruit quality were confirmed by many studies. At high salinity, Fruit cuticle became thicker and hardier while fruit firmness and turgor pressure were reduced Verkerke and Schols [15] and Verkerke., et al [24], which consequent lyproduce fruits with lower susceptibility to fruit cracking. Increasing the EC from 3.5 to $4.6 \mathrm{mS} / \mathrm{cm}^{-1}$ in a greenhouse tomato markedly minimized fruit cracking incidence by 68\% Chrétien., et al [25]. Also, tomato fruit color indices was better with high EC of nutrient solution Sonneveld and Van Der Burg [14], as well as uneven ripened fruit were reduced Sonneveld and Van Der Burg [14]. Similarly, Borghesi., et al [26], proposed that salinity increase markedly enhanced the color development in tomato fruits. On the other hand, the number of BER fruits was negatively affected with salinity increases Adams and Ho [20], De Kreij [27], Ho [23], and Willumsen., et al. [28]. Cultivars with small fruit size, and high $\mathrm{Ca}^{2+}$ uptake efficiency were less susceptible to BER Adams and Ho 1995.

\section{Organoleptic and nutritional value}

Beneficial effect of increased salinity on quality aspects of tomato fruit such as taste, flavor and bioactive ingredients have been reported by several previous investigations $[29,30]$. In this concern, enriching the nutrient solution EC by up to $34 \mathrm{mMNa}$ Clmarkedly increased vitamin $\mathrm{C}$ and carotenoids as well as, total phenols and antioxidant activity [31]. Who added that, citric acid and TSS contents were increased under saline conditions showing that salinity had positive effects on taste and flavor of tomato fruits? Conversely a remarkable reduction of total fresh yield (40\%) was detected with the highest salinity level, which indicate that moderate salinity levels are better for high quality with out reducing the total yield. Similar findings in terms of sensorial quality aspects and antioxidants content have been informed by Wu., et al. [32] who observed that TSS and lycopene content were increased by 23 and $85 \%$, respectively due to salinity increase up to $4.5 \mathrm{dS} \mathrm{m}^{-1}$, where salinity treatments had no significant effect of on total yield. Furthermore, Moya et al., [33] reported that although salinity treatments at the highest EC levels ( $4.5 \mathrm{dS} \mathrm{m}^{-1}$ ) significantly reduced the total and commercial yield and fruit size ( $\mathrm{dS} \mathrm{m}^{-1}$ ) but, lycopene, ascorbic acid, total phenolics content and total antioxidant activity were significantly increased by $6.3 \%, 8.8 \%, 8.3 \%$ and $11.1 \%$, respectively. Also, Sait., et al [34], reported that salinity treatment at late growth stage with saline nutrient solution ( $8 \mathrm{dS} \mathrm{m}^{-1}$ ) significantly increased TSS content than control and had lower blossom-end rot incidence than salinity treatments at early growth stage. Likewise, Borghesi., et al. [26] investigated the response of four tomato genotypes with different amounts of anthocyanins to two salinity levels (3.5 and 5.5 $\mathrm{dS} \mathrm{m}^{-1}$ ) and found that increasing effect of salinity was genotype dependent. The results of this study indicate that using salinity has a great potential tool for increasing bioactive compounds content comparing to genetic engineering or plant breeding tools. However, [35] observed that tomato fruits with salinity treatment significantly had higher lycopene content. They added that, salinity treatment accelerate respiration and ethylene production, which speed up ripening. On the contrary, the disadvantageous effects of salinity stress on tomato fruit quality were confirmed by many studies. According to Ali and Ismail [36], they reported that the application 
of saline nutrient solution (100 $\mathrm{mM} \mathrm{NaCl}$ ) caused a significant decrease of carotenoids and ascorbic acid. Likewise, De Pascale., et al. [37] proposed that salinity levels higher than $4.4 \mathrm{dS} \mathrm{m}^{-1}$ caused as ever reduction of carotenoids and lycopene content,

\section{Conclusions}

Although salinity is associated with a decrease of total yield and fruit size for most of the vegetable crops, moderate salinity levels might enhance flavor aspects and nutritional value yielded fruits and increase its added value in the market with higher prices balancing for the yield losses.

Since there are a lot of research investigations concerning the effect of salinity on tomato fruit quality, it could be recommended that, manipulation of the salinity application is an effective method for the improvement of fruit quality particularly in terms of visual appearance, chemical composition and bioactive ingredients content. On the other hand, the adverse effects of salinity on total yield and fruit size have also to be more considered to balance between the obtained yield and the quality of produced fruits. However, improving tomato fruit quality and yield can be attained by implementing a proper and reliable salinity and irrigation management.

\section{Bibliography}

1. Bucheli P., et al. "Definition of nonvolatile markers for flavor of tomato (Lycopersicon esculentum Mill.) as tools in selection and breeding". Journal of Agricultural and Food Chemistry 47.2 (1999): 659-664.

2. Malundo., et al. "Flavor quality of fresh tomato ( Lycopersicone sculentum Mill.) as affected by sugar and acid levels". Postharvest Biology and Technology 6 (1995): 103-110.

3. Krinsky NI. "Effects of carotenoids in cellular and animal systems". The American Journal of Clinical Nutrition 53 (1991): 238-246.

4. Krinsky NI. "Anticarcinogenic activities of carotenoids in animals and cellular systems". in: Emers I., Chance B. (Eds.), Free Radicals and Aging, Verlag, Basel, (1992): 227-234.

5. Franscis AR., et al. "Modifying role of dietary factors on the mutagenicity of aflatoxin B1: in vitro effect of plant falvonoids". Mutation Research 222 (1989): 393-401.

6. Verma AK., et al. "Inhibition of 7,12-dimethylbenz(a)anthracene and Nnitrosomethylurea induced rat mammary cancer by dietary flavonolquerceti". Cancer Research 48 (1988): 5754-5788.
7. Chen $\mathrm{Z}$ and Miller A.R. "Steroid alkaloids in Solanaceous vegetable crops: Chemistry, biochemistry, distribution, horticulture and toxicology". Horticulture Review 25 (2000): 171-196.

8. Grolier P and Rock E. "The composition of tomato in antioxydants: variations and methodology". Proc. Tomato and Health Seminar. Pamplona, Spain, (1998): 87-94.

9. Borgognone D., et al. "Changes in biomass, mineral composition, and quality of cardoon in response to NO3:Cl- ratio and nitrate deprivation from the nutrient solution". Frontiers in Plant Science 7 (2016): 978

10. Tomasi N., et al. "New solutions for floating cultivation system of ready-to-eat salad: a review". Trends in Food Science and Technology 46 (2015): 267-276.

11. Kyriacou MC and Rouphael Y. "Towards a new definition of quality for fresh fruits and vegetables". Scientia Horticulturae 234 (2018): 463-469.

12. Dorais M., et al. "Improving tomato fruit quality by increasing salinity: effects on ion uptake, growth and yield". XXV International Horticultural Congress, Brussels August 2-7, 1998 Acta Horticulturae 511 (2000): 185-196.

13. Massey DM., et al. "Some responses of tomatoes to salinity in nutrient film culture". in: Glasshouse Crops Res. Inst. Annu. Rep., (1984): 60-62.

14. Sonneveld C., et al. "Sodium chloride salinity in fruit vegetable crops in soilless culture". Netherlands Journal of Agricultural Science 39 (1991): 115-122.

15. Verkerke W and Schols M. "The influence of EC level and specific nutrients on the firmness, taste and yield of tomato, Glasshouse". Crops Research (1992): 37.

16. Cuartero J., et al. "Tomato and salinity". Scientia Horticulturae 78 (1999): 83-125.

17. Abbott JD., et al. "Water management of greenhouse tomatoes". Hort Science 20 (1985): 688-690.

18. Abbott JD., et al. "Effects of irrigation frequency and scheduling on fruit production and radial fruit cracking in greenhouse tomatoes in soil beds and in soil-less medium in bags". Scientia Horticulturae 28 (1986): 209-217. 
19. Cortés C., et al. "Relationship between radial and concentric cracking of tomato fruit". Scientia Horticulturae 21 (1983): 323-328.

20. Adams P and Ho LC. "The susceptibility of modern tomato cultivars to blossom-end rot in relation to salinity". The Journal of Horticultural Science 67.6 (1992): 827-839.

21. Adams P and Ho LC. "Differential effects of salinity and humidity on growth and Ca status of tomato and cucumber grown in hydroponic culture". Acta Horticulturae 401 (1994): 357-363.

22. Belda RM and Ho LC. "Salinity effects on the network of vascular bundles during tomato fruit development". The Journal of Horticultural Science 68 (1993): 557-564.

23. Ho L.C. "The physiological basis for improving tomato fruit quality". Acta Horticulturae 487 (1999): 33-40.

24. Verkerke W., et al. "Development of fruit firmness during growth period”. Glasshouse Crops Res. Stat., Naaldwijk (1991): 35 .

25. Chrétien S., et al. "High electrical conductivity and radiation based water management improve fruit quality of greenhouse tomatoes grown in rockwool". HortScience 35.4 (2000): 627631.

26. Borghesi E., et al. "Effects of salinity on carotenoids, anthocyanins, and color of diverse tomato genotypes". Journal of Agricultural and Food Chemistry 59.21 (2011) 11676-11682.

27. De Kreij C. Blossom-end rot, Compterendu de la reunion du 25 février, Cultilène, division d'Isover, St-Gobain, France (1992): 947-953.

28. Willumsen J., et al. "Yield and blossom-end rot of tomato as affected by salinity and cation activity ratios in the root zone". The Journal of Horticultural Science 71 (1996): 81-98.

29. Dorais M., et al. "Tomato (Solanum lycopersicum) health components: from the seed to the consumer". Phytochemistry Reviews 7 (2008): 231-250.

30. Schwarz D., et al. "Nutrient management in soilless culture in the conflict of plant, microorganism, consumer and environmental demands". Acta Horticulturae 843 (2009): 27-34.
31. Krauss S., et al. "The influence of different electrical conductivity values in a simplified recirculating soilless system on inner and outer fruit quality characteristics of tomato". Journal of Agricultural and Food Chemistry 54 (2006): 441-448.

32. Wu M., et al. "Effects of nutrient solution EC, plant microclimate and cultivars on fruit quality and yield of hydroponic tomatoes (Lycopersicum esculentum L.)". Acta Horticulturae 659 (2004): 541-547.

33. Moya C., et al. "Increased electrical conductivity in nutrient solution management enhances dietary and organoleptic qualities in soilless culture tomato". HortScience 52 (2017): 868872.

34. Saito T., et al. "Effects of salinity treatment duration and planting density on size and sugar content of hydroponically grown tomato fruits". Journal of the Japanese Society for Horticultural Science 75 (2006): 392-398.

35. Wu M., et al. "Effects of high electrical conductivity of nutrient solution and its application timing on lycopene, chlorophyll and sugar concentrations of hydroponic tomatoes during ripening". Scientia Horticulturae 116 (2008): 122-129.

36. Ali HEM and Ismail GSM. "Tomato fruit quality as influenced by salinity and nitric oxide". Turkish Journal of Botany 38 (2014): 122-129.

37. De Pascale S., et al. "Irrigation with saline water improves carotenoids content and antioxidant activity of tomato". The Journal of Horticultural Science and Biotechnology 76 (2001): 447-453.

Volume 3 Issue 8 August 2019

(C) All rights are reserved by Fawzy ZF., et al. 